\title{
FLOOD INUNDATION MAPPING ALONG THE PROPOSED DIKE SYSTEM OF THE CAGAYAN DE ORO RIVER: THE SENDONG SCALE FLOOD
}

\author{
D.S. LO, J. TAAT, C.A.P. LAPURE, A.A.O. PADUGANAN, G.L.B. LAMPARAS \& K.M. BACULIO \\ XU Engineering Resource Center, Xavier University - Ateneo de Cagayan, Philippines.
}

\begin{abstract}
In recent years, Cagayan de Oro has experienced the damaging impacts of flooding. In December 2011, Tropical Storm Sendong (Washi) caused the most devastating flood in the city's history which caused unparalleled damages and casualties. To mitigate the impacts of river flooding, the Department of Public Works and Highways (DPWH) has instituted the Flood Risk Management Project - Cagayan de Oro River which proposes the construction of a $12-\mathrm{km}$ dike system along the river. However, the dike system is designed for a Pablo scale flood which is estimated at 25-year return period, as compared to a Sendong scale flood which is approximated at 50-year return period. This study aims to determine the flood inundated area along the Cagayan de Oro River considering the proposed dike system under a Sendong scale flood. A high resolution Digital Terrain Model (DTM) derived from Light Detection and Ranging (LiDAR) data was used. Flood profiles were then determined using a one-dimensional steady-state flow model. After running through 66 models, the final model is used to simulate the flood behavior with the proposed dike system. Results show that majority of the areas along the river are protected by the dike, thus conforming to the Pablo scale flood design. However, under a Sendong flood, results show that some areas along barangays Carmen, Balulang, and Macasandig could be flooded, with a total area of approximately 37 hectares. It is recommended that concerned government agencies revisit and review the design details before full implementation to ensure a sustainable flood mitigation project.

Keywords: dike, disaster, flood, LiDAR, Sendong.
\end{abstract}

\section{INTRODUCTION}

Floods are natural hazards which may cause loss of lives and damage to infrastructures and properties of vulnerable communities. An average of twenty tropical cyclones enter the Philippine Area of Responsibility every year, about seven or eight of which hit land and inflict considerable damages. In recent years, Cagayan de Oro City, which serves as the major gateway to various destinations in Mindanao, has experienced deadly and costly flooding. In January 2009, a tropical depression caused the flooding of major business districts and highways. Then in December 2011, rains brought by Tropical Storm Sendong (Washi) made two of the city's river systems rose to unprecedented levels, it became one of the most devastating and deadly events in the country's recent history. Sendong claimed 1,259 lives, 6,071 injured, 182 missing, and caused Php 1.7 billion cost of damages [1].

Since Cagayan de Oro City has been experiencing major flood events, projects to mitigate the risks to flooding have been proposed. One of these projects is the Flood Risk Management Project - Cagayan de Oro River (FRIMP-CDOR) jointly planned and to be implemented by the Department of Public Works and Highways (DPWH) and the Japan International Cooperation Agency (JICA). DPWH and JICA reviewed and updated previous master plans and 
feasibility studies based on the investigation of latest topographic conditions, and current policies of the Philippine Government for flood mitigation.

The main objective of the FRIMP-CDOR is to mitigate flood risk along the Cagayan de Oro River. The main structural component is to construct a 12-km dike system and floodwalls in the city where the river traverses. According to the project's Final Report, the dike system has a design discharge of a Sendong scale flood, which is approximately a 50-year return flood. However, it was also stated that the short-to-middle term core components of the project can only withstand a 25-year return flood [2].

As a result, during the 5th Board of Stakeholders Meeting of the Cagayan de Oro River Basin Management Council (CDORBMC) on March 2014, it was formally pronounced that Xavier University - Ateneo de Cagayan should coordinate with the DPWH-JICA FRIMPCDOR Team in coming up with an independent study of the proposed project. Therefore, this study aimed to determine the inundated area along the proposed dike system of the Cagayan de Oro River considering the Sendong scale flood.

\section{METHODOLOGY}

The study involved eight phases as shown in Fig. 1. Each of these is briefly discussed in the following sections.

\subsection{Study area and data used}

The Cagayan de Oro River traversing in Cagayan de Oro City is the last reach of the Cagayan de Oro River Basin that discharges to the Macajalar Bay. The boundary of the river basin is overlaid on the study area as shown in Fig. 2b. The primary consideration of delineating the study area is to include the FRIMP-CDOR dike system that stretches from Barangay Balulang down to the river mouth at Macajalar Bay, which is approximately 12 kilometers in length. Figure $2 \mathrm{c}$ shows the location of the proposed dike system over the study area.

Data used are Light Detection and Ranging (LiDAR) Orthophotos and Digital Terrain Model (DTM) which includes bathymetric data of the river. The topography and elevation of the channel were extracted and used together with the DTM to obtain the river geometry and in establishing the river cross-section cutlines. To be consistent with the DPWH-JICA study, design discharges of Pablo (Bopha) and Sendong (Washi) at 3,300 $\mathrm{m}^{3} / \mathrm{sec}$ and $5,000 \mathrm{~m}^{3} / \mathrm{sec}$ respectively were adapted based from the FRIMP-CDOR Final Report. Actual Flood Maps during Pablo and Sendong events were also gathered and used for calibrating and validating the hydraulic models.

The land use classification of the study area is also important for two main reasons: (1) it characterizes the surface roughness through which flood water flows, which affects the hydraulic model through the Manning's coefficient values, and (2) it describes the area over which flooding might happen, thus useful for disaster risk management strategies.

Landsat 8 imagery dated May 22, 2013 having a $30 \times 30$-meter pixel resolution is used to define the land use characteristics of the study area. This image was chosen because it is close to the date of acquisition of the LiDAR data which was on April 26-27, 2013.

Three independent sets of training samples using 28, 29 and 30 Region of Interest (ROI) were used to run the Spectral Angle Mapping Tool in the Geographic Information System (GIS) software to execute the land use classification. These runs resulted to three independent land-use classification maps. These maps were then validated using three sets of 50 ROI samples to check the accuracy of the results. The final land use classification map used 


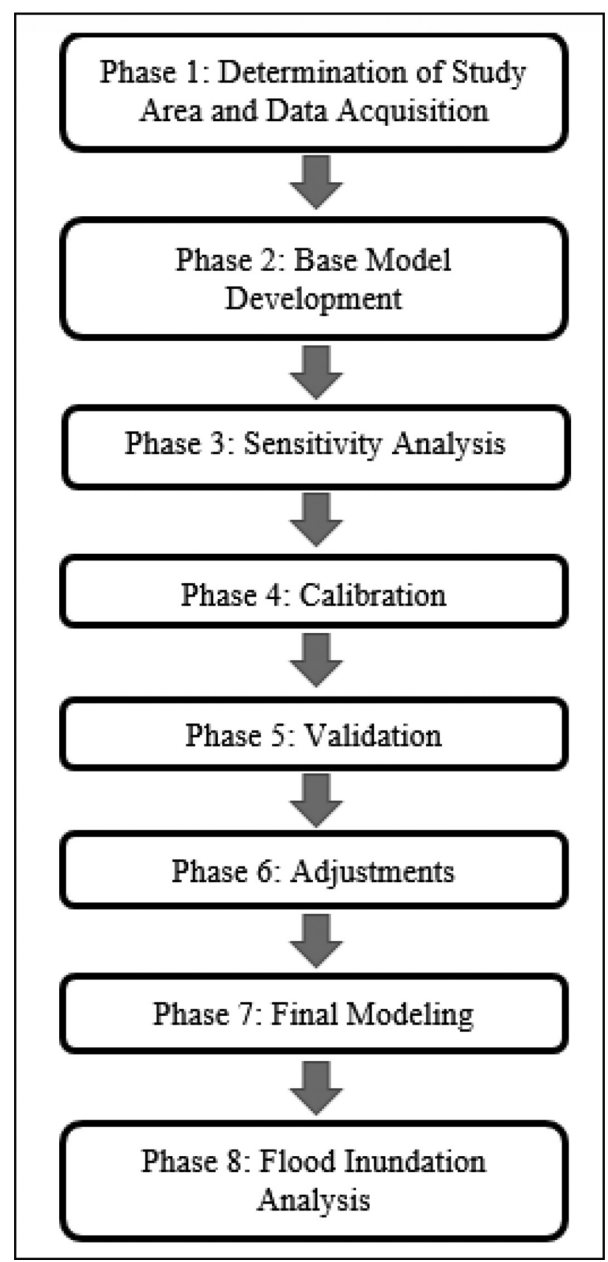

Figure 1: Research design.

in this study, which includes five land use signatures, is shown in Fig. 2d. Corresponding Manning's coefficient values for each land use classification were then based from existing literatures [3, 4].

However, because HEC-RAS, the hydraulic modeling software used in this study, allows only twenty Manning's coefficient values per cross-section, the resulting land-use raster image shown in Fig. $2 \mathrm{~d}$ had to be re-sampled from a $30 \times 30$-meter cell to a $150 \times 150$-meter cell using "majority" re-sampling technique in the GIS software. This re-sampled land use classification map would then be directly exported to the hydraulic model in HEC-RAS.

\subsection{Base model development}

A hydraulic base model was developed from known and hypothetically assumed parameters. The base model would quantitatively and visually describe the flood inundation through a map. It would then be used to serve as a basis for comparison of the results of the series of sensitivity analyses in Phase 3. 


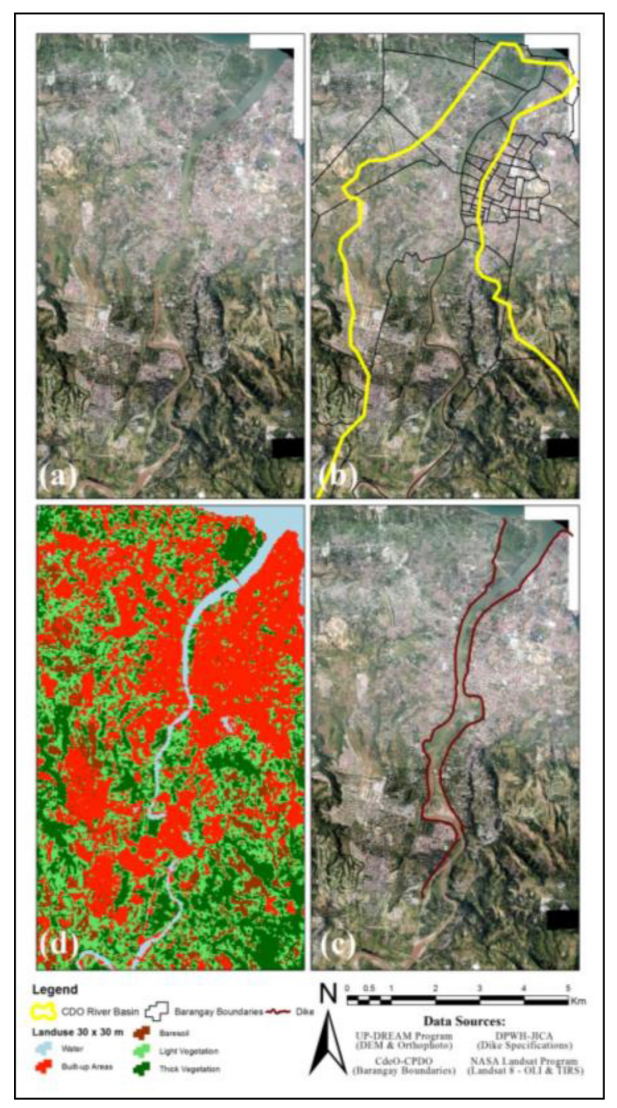

Fig ure 2: Study area.

In creating the hydraulic base model and consequent models in this study, a high resolution DTM was used to extract details of the topography of the study area. The LiDAR-based DTM used has a spatial resolution of $0.50 \mathrm{~m}$. HEC-GeoRAS was used to generate the channel geometry required by HEC-RAS.

HEC-RAS was then run to simulate a one-dimensional steady state sub-critical flow condition. HEC-RAS models would then produce tabular and graphical outputs of the flood. Free water surfaces and predicted cross-section inundations were then exported back to HECGeoRAS to improve visualization of the flood inundation mapping.

Hec-GeoRAS models are then further exported to the GIS software where the graphical geo-representation of the flooded areas were overlaid the DTM. This final step would generate a spatial extent of the flood inundation as well as its corresponding flood depth.

\subsection{Sensitivity analysis}

Sensitivity analysis would determine how each physical and calculated parameter used in modeling affect the behavior and results of the final hydraulic model. Sensitivity analyses were run for the following parameters: (1) discharge, (2) Manning's coefficient based from land use, (3) cross-section filter points, (4) normal depth, (5) stream centerline and flowpaths, (6) cross-section cutlines, and (7) levees. The results of the sensitivity analysis would then 
determine which parameters to improve, to adjust, or to retain, to come up with an improvised hydraulic model.

Percentage match was used in evaluating the result of each model compared with the base model, computed as:

$$
\text { Percentage Match }(P)=\left(\frac{A_{b p}}{A_{b}+A_{p}-A_{b p}}\right) \times 100 \%
$$

where $A_{b}$ is the predicted area of inundation of the base model, $A_{p}$ is the predicted area of inundation of each trial in each parameter, and $\mathrm{A}_{\mathrm{bp}}$ is the area that both exist in the predicted area of the base model and in the trial model. The value of $\mathrm{P}$ varies between $100 \%$ when what's predicted in the base model and the trial model perfectly overlaps, and $0 \%$ when no overlap between the base model and the trial model exist.

\subsection{Calibration}

Calibration of the improvised hydraulic model is necessary to enhance the model as compared to a referenced standard. For this study, the most appropriate flood event to be used as reference is the December 2012 Super Typhoon Pablo (Bopha) Flood since most parameters used in the model (e.g. DTM, land use) are dated close to the said flood event.

In calibrating the improvised hydraulic model, the design discharge of Pablo as indicated in the FRIMP-CDOR Final Report was adapted. The actual flood map of Pablo published by the Xavier University Engineering Resource Center (XUERC) was used as reference to compute the percentage match $(\mathrm{P})$ between the results of the calibrated hydraulic models as compared to the actual Pablo flood footprint.

Revisions of the hydraulic models during calibration were documented, and the top five hydraulic models were subjected to validation in Phase 5.

\subsection{Validation}

In developing hydraulic models, validation is another necessary step to create an accurate and credible model [5]. In this study, the top five hydraulic models calibrated in Phase 4 were validated using the Sendong flood event.

Similarly, the design discharge of Sendong as indicated in the FRIMP-CDOR Final Report was adapted. The actual flood map of Sendong produced by XUERC, which was also used as reference by the DPWH-JICA FRIMP-CDOR Team, was used to compute the percentage match $(\mathrm{P})$ to compare predicted and historical flood footprints. After running validation of these models, a final hydraulic model was then chosen.

\subsection{Adjustments}

After choosing the final hydraulic model, further adjustments of some computational parameters were refined. Due to the limitations of the hydraulic model (e.g., one-dimensional approach of HEC-RAS, debris not considered) the calculated parameters needed to be adjusted until a practical best-fit flood footprint is achieved.

The adjusted hydraulic model was again validated against the Sendong flood event, and finally verified back against the Pablo flood event to evaluate the credibility of the model after 
several parameters had been adjusted. In this study, this calibrated, validated, and adjusted hydraulic model is then called as the "Final Model without Dike."

\subsection{Final modeling}

The last phase of hydraulic modeling is the final modeling with the dike system. Dike location, geometry and elevations were integrated in the "Final Model without Dike" to create what is called as the "Final Model with Dike."

Using GIS tools, the dike system and details stipulated in the FRIMP-CDOR Final Report were georeferenced over the high-resolution LiDAR-based orthophotos. The dike length and location were then digitized with unique elevation values. The dike system elevations at certain cross-sections were inputted in HEC-RAS and simulations were run. Similar post-processing techniques were then employed to visualize the flood inundated areas and corresponding flood depths.

\subsection{Flood inundation analysis}

Analysis of the results of the "Final Model with Dike" against the Pablo scale and the Sendong scale floods were recorded and documented in detail. In particular, flooded areas and portions where the dike will possibly overflow were identified.

Predicted flood footprints were overlaid the land use profile to describe the kind of habitat or property that could be affected. Political boundaries were also overlaid to identify which barangay could be flooded. These and other details would be the basis for the recommendations for concerned government agencies to review the design details. The results may also serve as reference for disaster risk management strategies both at the institutional and community levels.

\section{RESULTS AND DISCUSSION}

\subsection{Model development}

\subsubsection{Land use classification}

As previously shown in Fig. 2d, five land use classes were identified within the study area, namely: built-up (urban and built-up land), light vegetation (cropland and pasture), thick vegetation (deciduous, evergreen and mixed forest land), bare soil, and water (river, streams and canals). Each of these has a corresponding Manning's coefficient value used in the hydraulic model [3, 4].

The average accuracy of the land use classification at $30 \times 30$-meter spatial resolution as mapped in Fig. 2d is $73.33 \%$. While that of the re-sampled land use classification at $150 \times$ 150 -meter spatial resolution directly exported to the hydraulic model is $78.67 \%$. These values conform to widely acceptable levels of accuracy used in various remotely sensed land-use classification studies [3].

\subsubsection{Sensitivity analysis}

Of the seven parameters subjected to sensitivity analysis, four were found sensitive, these are: (1) discharge, (2) Manning's coefficient based from land use, (3) cross-section cutlines, and (4) levees.

These findings imply the following insights which are essential in improving then calibrating the hydraulic models: (1) the model must use the right amount of discharge to correspond a particular flood event; (2) the model requires the most accurate possible land use to have a good estimate of the Manning's coefficient; (3) whenever possible, the model must have the 


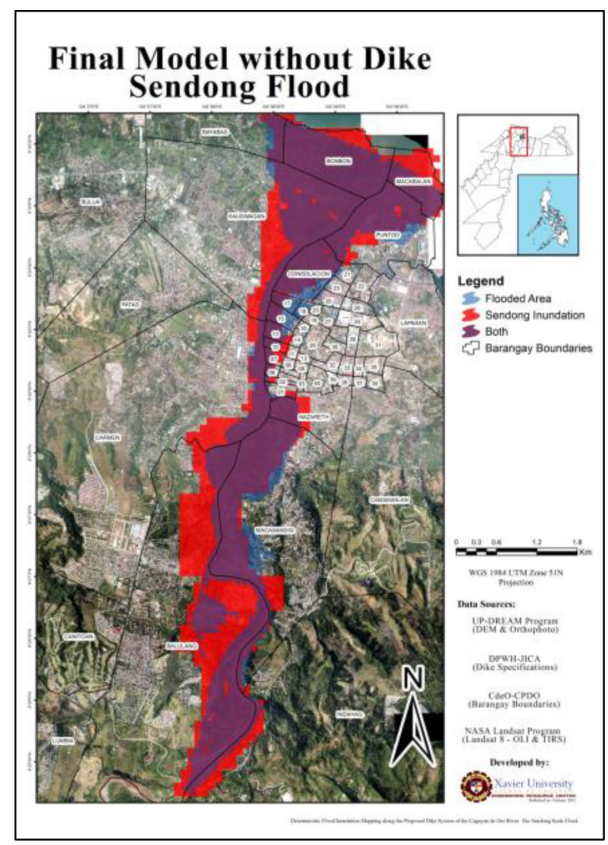

Figure 3: Flooded area that matched: model vs. Actual sendong event.

most practical number of cross-section intervals that extend throughout the floodplain; and (4) the levees can be natural or artificial like the dike system, and they must been keenly and constantly adjusted particularly because HEC-RAS utilizes one-dimensional flow and does not consider natural lateral flow.

\subsubsection{Calibration, validation, and adjustments}

From Base Model (Model 1.0) to an Improvised Model (Model 2.0), a total of eight independent hydraulic models were generated to calibrate with the Pablo flood event, coded as Model 2.1 to 2.8. It is important to note that only the computational parameters (cross-section cutlines, levees) were altered since the physical parameters (discharge, land use, bathymetry, and topography) already utilized real values. The top five calibrated hydraulic models have percentage match (P) of: 63.92\% (Model 2.3), 63.29\% (Model 2.2), 62.40\% (Model 2.6), $62.33 \%$ (Model 2.4), and 62.18\% (Model 2.5). These models were then subjected to validation. And among these five models subjected to validation with the Sendong flood event, Model 2.4 has the highest percentage match (P) of 55.03\%.

Four more adjusted hydraulic models were further generated from Model 2.4 to improve the percentage match with the Sendong flood event, coded as Model 3.1 to Model 3.4. And among these four models, Model 3.4 scored highest at percentage match (P) of 64.53\%. This hydraulic model thus became the "Final Model without Dike."

Other than the percentage match, it should be noted that the "Final Model without Dike" predicts a lesser total flooded area compared to the actual Sendong flood footprint. Figure 3 shows the model's predicted flooded area (blue), the actual Sendong flood footprint (red), and the flooded area that matched (violet). This hydraulic model was also verified back with the Pablo flood event and resulted to a percentage match (P) of 58.36\%, similarly illustrated in Fig. 4. 


\subsection{Final modeling and flood inundation analysis}

After running through 65 hydraulic models, the "Final Model without Dike" was finally generated with an accuracy of $64.53 \%$ compared to the actual Sendong flood event. This model was then overlaid with the FRIMP-CDOR dike system details to create the 66th hydraulic model generated in this study, called as the "Final Model with Dike." The Final Model with Dike was run to simulate flood inundation scenarios for a Pablo scale flood and a Sendong scale flood.

Figure 5 shows the simulated flood inundation map for a Pablo scale flood when the FRIMP-CDOR dike system would have been constructed. The results clearly conform to the design of the dike system that it can withstand a 25-year return flood event like that of Pablo, as indicated in the FRIMP-CDOR Final Report.

However, it is equally important to note the corresponding water level inside the dike system. Since dikes will naturally constrict the flow of water to prevent flooding inland, there would in effect be significant increase of water level inside the dike system; in this case reaching nine to ten meters in some narrow areas as shown in Fig. 5.

On the other hand, Fig. 6 shows the simulated flood inundation map for a Sendong scale flood when the FRIMP-CDOR dike system would have been constructed. It is surprising but good to note that the dike system could still contain most of the flood water even for a 50-year return flood like that of Sendong.

However, the significant increase of water level inside the dike system must again be emphasized, in this case reaching eleven to twelve meters in some constricted areas as indicated in Fig. 6. These areas (in both Sendong and Pablo scenarios) should be duly noted for special structural and geotechnical design considerations of the dike system, as well as for disaster preparedness strategies like evacuation routes and related operations.

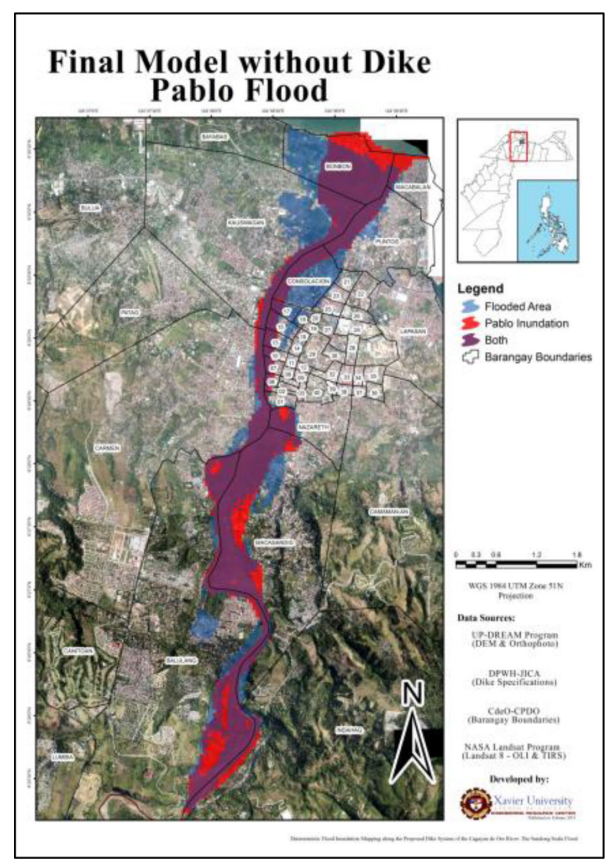

Figure 4: Flooded area that matched: model vs. Actual pablo event. 


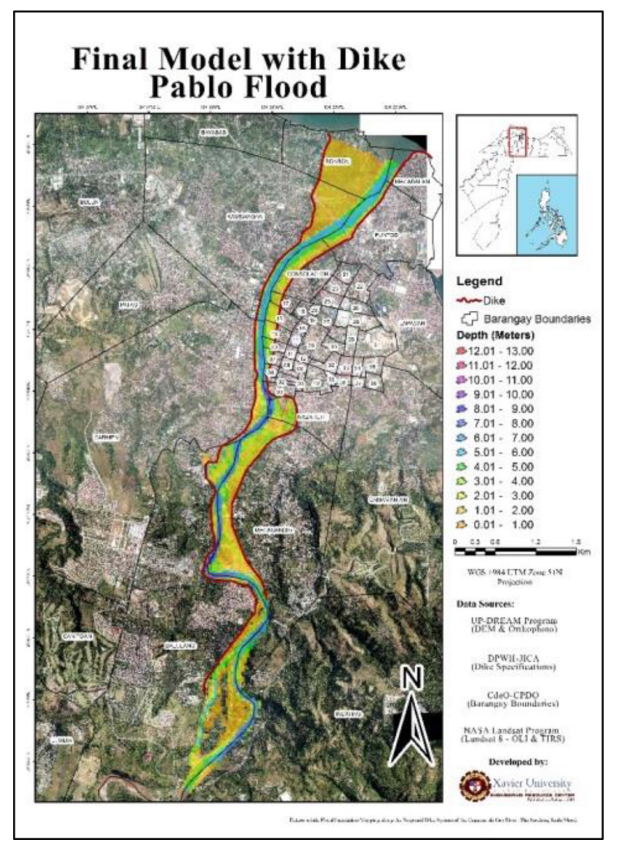

Figure 5: Final model with dike: pablo scale flood.

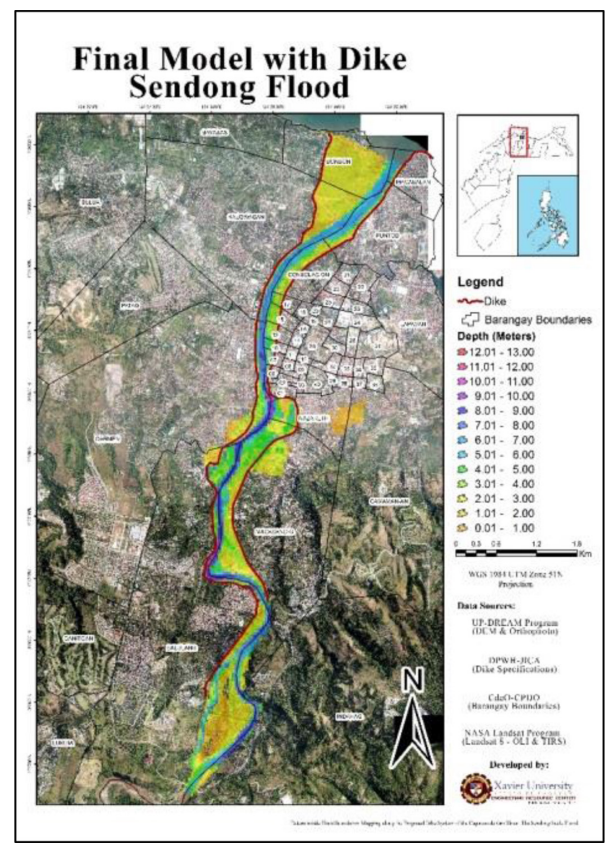

Figure 6: Final model with dike: sendong scale flood.

Figure 6 also clearly depicts that there are some parts of the dike system that would possibly overflow. And this would cause flooding over some areas of barangays Carmen, Balulang and Macasandig, with a combined area of approximately 37 hectares. 


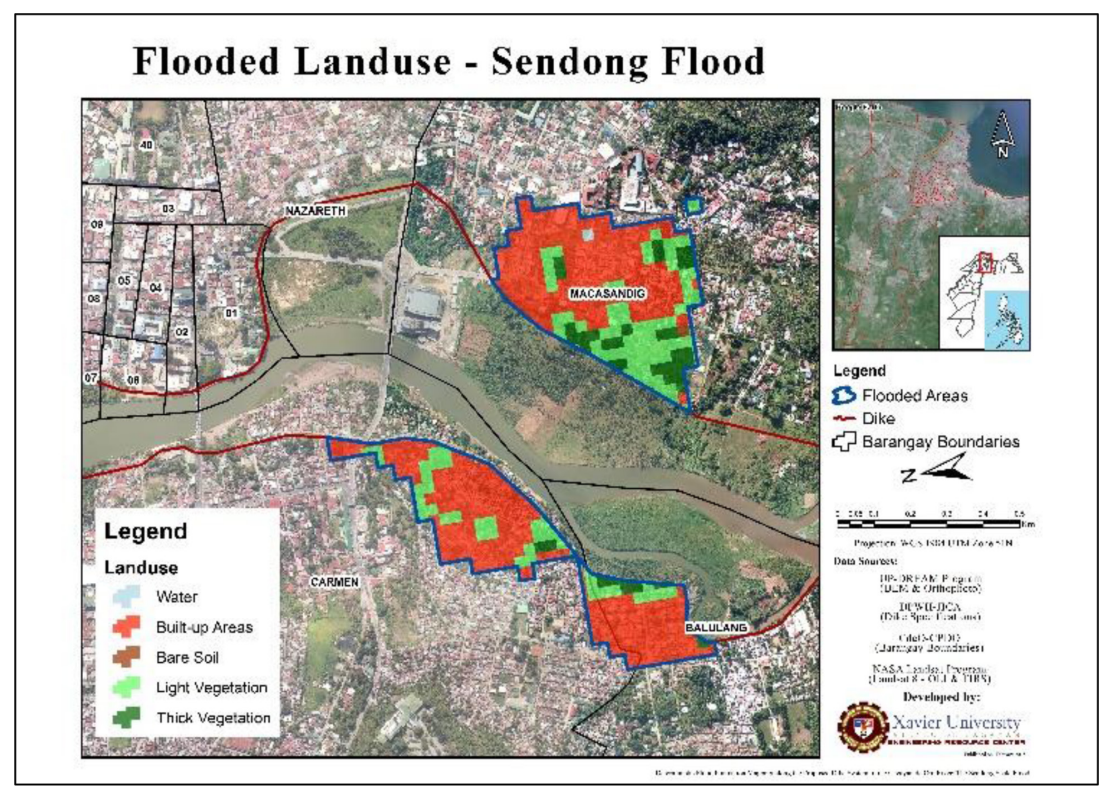

Figure 7: Flooded areas over land use: sendong scale flood with dike.

Overlaying the simulated flood footprint above the land use classes in these flooded areas reveal that most of these affected areas are built-up (24.79 hectares), particularly residential and densely populated, as shown in Fig. 7.

\section{CONCLUSION AND RECOMMENDATIONS}

After running through rigorous hydraulic modeling procedures and techniques, the study finally generated the "Final Model without Dike" which can predict approximately 65\% match compared to the actual Sendong flood event. This model also predicts a lower total flooded area as compared to the actual Sendong flood footprint.

Integrating the FRIMP-CDOR dike system to the existing model, the study finally generated the "Final Model with Dike," which was used to evaluate the flood inundation scenarios when the FRIMP-CDOR dike system would have been built.

Results show that for a Pablo scale flood, the dike system could contain the flood water as its design claims in the FRIMP-CDOR Final Report. However, for a Sendong scale flood, as much as most of the flood water could still be contained within the dike system, there would be some possible dike overflow that could cause some flooding over barangays Carmen, Balulang and Macasandig, with a combined area of approximately 37 hectares. Most of these flooded areas are densely populated residential use.

However, it should be noted that the model is able to predict a lesser total flooded area as compared to the actual Sendong flood event. This could mean that the predicted flood inundation scenario for a Sendong scale flood might have been underestimated. Thus, utmost caution and more conservative planning strategies and design considerations must be adhered.

Of equal importance to note are the resulting water levels inside the dike system which could reach eleven to twelve meters in some constricted areas, should a Sendong scale flood happen when the dike system would have been constructed. This significant rise of water level on the river would obstruct several urban drainage lines that currently drain to the Cagayan de Oro River, especially during heavy rains in the city proper. 
With these results, it is therefore strongly suggested for the concerned government agencies to review and revisit the detailed engineering design of the dike system, while major structural components of the dike project hasn't been implemented yet. Other than the location to where floodwaters could possible inundate, the water level inside the dike system is an equally critical parameter to consider as this may have implications in the structural and geotechnical integrity of the dike system.

Of course, it should also be noted that the model comes with some inherent limitations. Further improvements can still be made such as modeling in two- or three- dimensions, using an unsteady state flow, considering the bridges along the river and the debris in the flood water.

Nevertheless, the results of this study may serve as reference for effective disaster preparedness and response planning strategies at both the institutional and community levels. Local Disaster Risk Reduction and Management Plans, as well as Flood Contingency Plans of riverside communities may need to be updated or enhanced considering these possible flood scenarios when the dike system would have been built in their barangays.

The results could also be used as a reference for evaluating and planning a truly sustainable urban development for the city. A dike system of this magnitude is a lifetime commitment of infrastructure maintenance. It is essential that the stakeholders - the implementing government agencies, the local government, and the local communities, embrace a mutual understanding and shared responsibility of what is to be built and how to make it useful beyond their lifetime.

Finally, as a side note, it is equally important to emphasize the connectivity of the ridge and rivers - that no matter how much infrastructure is built downstream, the fact remains that the river discharge is influenced by the condition of the river basin. Therefore, it is also wise and prudent to introduce and invest non-structural and environmental measures to rehabilitate and enhance the ecological integrity of the river basin upstream.

\section{ACKNOWLEDGEMENTS}

The authors express deep gratitude to the University of the Philippines - Disaster Risk and Exposure Assessment for Mitigation (UP-DREAM) Program for the LiDAR-based data used in this project. Special thanks are also due to NEDA-10 and DPWH-10 for providing technical details and explanatory notes of the proposed FRIMP-CDOR dike system. The authors also wish to thank the Xavier University Engineering Resource Center (XUERC) for the historical Sendong and Pablo flood footprint maps, and for jointly funding this project with the XU Kinaadman Research Center.

\section{REFERENCES}

[1] NDRRMC. Sitrep No. 46: Effects of Tropical Storm "Sendong" (Washi) and Status of Emergency Response Operations, NDRRMC, Manila, 2012.

[2] JICA, Preparatory Survey for Flood Risk Management Project for Cagayan de Oro River in the Republic of the Philippines. JICA, Philippines, 2013.

[3] Rozenstein, O. \& Karnieli, A., Comparison of methods for land-use classification incorporating remote sensing and GIS inputs. Applied Geography, 31(2), pp. 533-544, 2011. http://dx.doi.org/10.1016/j.apgeog.2010.11.006

[4] Anderson, J.R., Hardy, E.E., Roach, J.T. \& Witmer, R., A land use and land cover classification system for use with remote sensor data. USGS, USA, 2001.

[5] Banks, J., Carson, J., Barry, L. \& David, N., Discrete Even System Simulation, 5th edn., Pearson Education, USA, 2010. 